\section{O Juiz e o princípio do contraditório}

Ensaio destinado à coletânea em homenagem a Alfredo Buzaid

Carlos Alberto Alvaro de Oliveira

Professor da Universidade Federal do Rio Grande do Sul

SUMÁRIO

Resumo: 1. Introdução; 2. Divisão do trabalho desenvolvido pelos sujeitos prócessuais; 3. Balizamentos para a construção de uma nova concep̧̧ão do princípio; 4 . Consideraçōes conclusivas.

1. O contraditório constitui, sem dúvida, elemento essencial ao fenômeno processual, especialmente pela imprescindível participação dos interessados no iter de formação do provimento destinado a interferir em sua esfera jurídica.

Não se pode deixar de reconhecer, no entanto, que a intervenção dos interessados deve ser exercida mediante eqüitativa distribuição dos respectivos poderes, faculdades e deveres, de modo a haver efetiva correspondência e equivalência entre as posições contrapostas. Por outro lado, tal estrutura, necessariamente dialética, deve condizer com a dinâmica dialética do processo: a simetria, mútua implicação e substancial paridade das posições subjetivas traduz-se, para cada um dos participantes, na possibilidade de intervir de forma não episódica e, sobretudo, de exercer um conjunto de controles, reações e escolhas, bem como a necessidade de se submeter aos controles e reações alheias ${ }^{1}$.

Com inteiro acerto, acentua Betti encontrar esteio o princípio do contraditório em duas ordens de consideração. A primeira, de conteúdo lógico, em vista de que a própria ação deve ser aforada contra quem o provimento terá eficácia; a segunda, por razões práticas, em virtude de facilitar-se, por meio da atividade contraposta das partes, com mediação do juiz, a investigação do material fáctico e jurídico da causa ${ }^{2}$.
$\mathrm{Na}$ realidade, impõe-se atentar à natureza essencialmente dialética do processo. De um lado, a vontade do juiz nunca é totalmente soberana, pois de um ou outro modo condiciona-se à vontade e ao comportamento das partes, no que representam de iniciativa, estímulo, resistência ou concordância ${ }^{3}$. Quanto às partes, sua vontade e atividade tendem a se plasmar e adequar aos estímulos decorrentes do comportamento do juiz e do adversário ${ }^{4}$. Vale dizer: "(...) no processo, o juiz nunca está só. O processo não é um monólogo: é um diálogo, uma conversação, uma troca de propostas, de respostas, de réplicas; um intercâmbio de ações e reações, de estímulos e de impulsos contrários, de ataques e contra-ataques. Por isso, foi comparado a uma luta ou disputa esportiva; mas cuida-se de uma luta de persuasões e de uma disputa argumentativa" ${ }^{5}$

2. Quando se trata do princípio do contraditório, a visualização tende a se fixar nas partes, sem alcançar a figura do juiz, o que diminui, a nosso ver, o alcance da garantia. Por isso, antes de passarmos ao exame do conteúdo do próprio princípio do contraditório, tema principal do presente trabalho, cumpre verificar a posição das partes e do órgão judicial na dinâmica processual, principalmente em termos de divisão de trabalho.

Em primeiro lugar, impõe-se respeitado o princípio dispositivo, no sentido substancial ou próprio. Não pode haver dúvida,

R. Fac. Direito UFRGS, Porto Alegre, 9(1): 178-184, nov. 1993

hoje, de que cabe à parte autora a exclusiva iniciativa de iniciar o processo e determinar a res in iudicium deducta: a alegação dos fatos constitutivos essenciais (substrato da causa petendi), além de qualificar e dar vida ao pedido, forma ponte imprescindivel entre o direito material (afirmado in status assertionis) e o processo, a reforçar o caráter necessariamente instrumental deste em relação àquele.

Todavia, proposta a demanda e delimitados os seus contornos essenciais, constitui dever do juiz controlar o rápido, regular e leal desenvolvimento do processo, assumindo, quando for o caso, os meios probatórios, nos limites objetivos da causa. Aqui, não se pode deixar de distinguir as normas, poderes, deveres, faculdades e atos condizentes com o momento do pedido de tutela jurisdicional, das normas, poderes, deveres, faculdades e atos correspondentes à técnica e estrutura interna do procedimento.

Quando do aforamento da ação, a parte dispõe do seu interesse material (ainda hipotético) e, por consequiência, do poder de pedir a tutela jurisdicional. Já dentro do processo, as iniciativas, especialmente de conteúdo probatório, são escolhidas à vista da técnica própria do instrumento processual, conforme pareçam mais adequadas para atingir a finalidade desejada ${ }^{6}$.

Inexiste, porém, monopólio da parte quanto à instrução da causa, mesmo com referência a interesses puramente privados. Como bem se ressaltou, entre nós, "O problema aqui não é de disponibilidade ou indisponibilidade do interesse, mas de um instrumento com que o Estado aplica a norma ao caso concreto, atendendo, com isso, a um interesse seu", com o que, concedendo-se poderes instrutórios ao juiz, subtrai-se da parte o poder de direção formal do processo, passando ela à condição de colaboradora do órgão judicial ${ }^{7}$. A verdade é que não se pode mais aceitar o juiz inerte, de braços cruzados, e que encarava o processo como coisa das partes. E aí está o art. 130 do CPC para comprovar a proposição.

Não se esqueça, contudo, que mesmo o juiz mais competente não está inteiramente habilitado, sem a ajuda do advogado, a conduzir um processo complicado do ponto de vista prático. Ele não terá tempo e, ainda com a melhor boa vontade, o mesmo interesse dos representantes das partes, para classificar o material por elas trazido, processá-lo e formá-lo com independência. O juiz deve apenas preencher e suplementar as lacunas, não se podendo exigir, contudo, que compense com sua atividade a inércia das partes.

$\mathrm{Na}$ realidade, diante do inafastável caráter dialético do processo, deve se modificar de forma significativa o alcance do antigo brocardo da mibi factum, dabo tibi ius.

Antes de nada, afigura-se um tanto quanto arbitrário valorizar abstratamente a disquisição ou o juízo sobre o fato, como se tatalmente divorciados do juízo de direito.

Ademais, exibe-se evidente a relatividade da primeira parte do aforismo. A indicação do material fáctico da causa deixou de constuir tarefa exclusiva das partes.

Certamente, devem elas contribuir com os fatos essenciais, constitutivos da causa petendi, como acima se assinalou. Ao juiz, porém, não está vedado apreciar os fatos secundários, deles extraindo, direta ou indiretamente, a existência ou modo de ser do fato principal. De igual forma, mesmo em se tratando dos fatos principais, não fica excluída sua apreciação por exclusiva iniciativa do órgão judicial quando: a) refiram-se a uma situação de direito público ou de ordem pública (assim, v.g., a matéria concernente aos pressupostos processuais $e$ às condições da ação); b) digam respeito a fatos jurídicos extintivos e impeditivos in compatíveis com a pretensão exercida (v.g., pagamento, confusão etc.), desde que não constituam verdadeiro contradireito, vale dizer uma exceção em sentido substancial ${ }^{9}$. $E$ isto sem falar nos fatos constitutivos, modificativos ou extintivos do direito, capazes de influir no julgamento da lide, que o juiz, no momento de proferir a sentença, consoante a dicção do art. 462 do CPC, até de ofício pode tomar em consideração.

$\mathrm{O}$ mesmo se passa no concernente à valorização jurídica da realidade externa ao 
processo, tarefa em relação à qual podem e devem as partes aportar a sua cooperação.

Investigação dessa ordem de modo nenhum pode constituir, atualmente, labut exclusiva do órgão judicial ${ }^{10}$.

A intervenção do revel no processo, por exemplo, apesar do reconhecimento aí implicado da verdade dos fatos alegados pelo autor (CPC, art. 322, $2^{\underline{a}}$ parte), ocorre exatamente porque a revelia é restrita à matéria de fato, com abstração das questões de direito, em relação às quais permite-se à parte procurar persuadir o órgão julgador. Do ius fornecido pelos próprios litigantes, e não só pelo juiz, trata expressamente o art. 300 do CPC, ao fazer ônus do réu a alegação, na contestação, de toda a matéria de defesa, inclusive de direito. Não por outro motivo, admite-se formulem as partes alegações tanto em relação a questões de fato quanto de direito (v.g., art. 454, $\S 3^{\circ}$, do CPC).

Essas regras, e mesmo a expectativa de sucesso final na causa, demonstram a existência de um interesse primordial da parte em dar conhecimento ao tribunal da norma jurídica que, segundo ela, deve ser aplicada, embora inexista obrigação formal para tanto. O mesmo se passa em relação ao convencimento do órgão judicial, quanto à bondade da solução jurídica preconizada. E isto porque pode haver o risco de o juiz não "descobrir" a norma jurídica favorável ao litigante, ou de não a interpretar corretamente ${ }^{11}$. Não quer isto dizer, contudo, que se trate de um ônus da parte (mesmo em relação ao direito nacional), como pretende Baur ${ }^{12}$, pois, da falta de enunciação da regra jurídica adequada para a solução do caso, nem sempre decorre um prejuízo (de regra até improvável: iura novit curia $\bigwedge^{13}$.

As considerações até agora expendidas mostram, de forma suficiente, a ausência de nítida repartição de funções entre as partes e o órgão judicial. Ao contrário, da análise do que realmente se passa transparece claramente o entrelaçamento de ambas atividades, com mútua colaboração tanto na pesquisa dos fatos quanto na valorização jurídica da causa. Colaboração essa, acentue-se, possibilitada apenas pelo permanen180 te diálogo entre os sujeitos processuais, com comunicação das idéias subministradas por cada um deles: juízos históricos e valorizaçōes jurídicas que possam ser empregados convenientemente na decisão ${ }^{14}$

Nem se argumente, por outro lado, que a qualificação profissional do juiz e os amplos instrumentos de pesquisa a seu dispor afastariam, ou tornariam desnecessária, tal cooperação. Trata-se de visão dogmática e positivista, desautorizada pela complexidade da vida moderna. É sabido que a interpretação da regula iuris nasce de uma compreensão integrada entre $o$ sujeito $e$ a norma, geralmente não unívoca, com forte carga de subjetividade, até porque todo direito litigioso apresenta-se consubstancialmente incerto ${ }^{15}$

Exatamente em face dessa realidade é que se mostra inadequada a investigação solitária do órgão judicial; o monólogo consigo mesmo limita necessariamente a perspectiva do observador, enquanto o diálogo, em compensação, recomendado pelo método dialético, amplia o quadro de análise, constrange à comparação, atenua o perigo de opiniões preconcebidas e favorece à formacão de um juízo mais aberto e ponderado: "E o diálogo que corrige continuamente a lógica e não a lógica que controla o diálogo".

Ora, a possibilidade concedida aos litigantes, de pronunciar-se e intervir ativamente no processo, produz a inarredável conseqüência de não se sujeitarem, passivamente, à definição jurídica ou fáctica da causa efetuada pelo órgão judicial. E essa constatação, evidentemente, provoca imediato reflexo no conteúdo atribuível ao próprio princípio do contraditório, como veremos a seguir.

3. Da análise até agora desenvolvida, impõe-se afastar a possibilidade de que a parte possa ser considerada simples "objeto" do pronunciamento judicial, no iter procedimental: exibe-se ineliminável o seu direito de atuar de modo crítico e construtivo sobre o andamento do processo e o seu resultado, desenvolvendo a defesa das próprias razões antes da prolação da decisão. A matéria liga-se ao próprio respeito à dignidade humana, encontrando expressão, no âmbito processual, na Anspruch auf rechtlichen Gebor (pretensão de audiência jurídica, ou, em tradução livre, precisamente no princípio do contraditório). Demais disso, inadmissível fiquem os litigantes adstritos, pura e simplesmente, à diligente iniciativa do órgão judicante e ao seu empenho de chegar a uma correta definição da causa ${ }^{17}$.

Torna-se, assim, palpável a insuficiência do conceito do contraditório, tal como geralmente entrevisto na doutrina brasileira, ou seja, como mera ciência bilateral dos atos do processo e possibilidade de contraditá-los

Tal concepção, convém sublimar, encontra-se ainda fortemente atrelada ao prejuízo antigo de que o direito deveria ser dito exclusivamente pelo juiz, sem a interferência das partes. A realidade, porém, é muito mais complexa, a impor permanente disquisição em conjunto do órgão judicial e do participantes do litígio processual.

Ora, essa colaboração só se ostenta possível, do ângulo visual das partes, quando sabem elas ou podem saber de que depende, no caso concreto, o ponto de vista do órgão judicial. De modo nenhum pode-se admitir sejam as partes, ou uma delas, surpreendidas por decisão que se apóie, em ponto decisivo, numa visão jurídica de que não se tenham apercebido, ou considerada sem maior significado: o tribunal deve dar conhecimento de qual direção o direito subjetivo corre perigo. Permitir-se-á apenas o aproveitamento, na sentença, dos fatos sobre os quais as partes tenham tomado posição ${ }^{19}$.

Dentro da mesma orientação, a liberdade concedida ao julgador de escolher a norma a aplicar, independentemente de sua invocação pela parte interessada, consubstanciada no brocardo iura novit curia, não dispen sa a prévia ouvida das partes sobre os novo rumos a serem imprimidos à solução do litígio, em homenagem ao princípio do contraditório $^{20}$. Não se considere, aliás, rar a hipótese: são freqüentes os empecilho com que se depara o aplicador do direito, nem sempre solucionáveis com facilidade dificuldade geralmente agravada pela posição necessariamente parcializada do litigan-
, o que colabora para empecer visão clara respeito dos possíveis rumos do processo e de sua solução.

Mesmo a matéria que o juiz deva conhecer de ofício impõe-se pronunciada apenas com a prévia manifestação das partes, pena de infringência da garantia. Por sinal, é bem possível recolha o órgão judicial, dessa audiência, elementos que o convença, da desnecessidade, inadequação ou improcedência da decisão que iria tomar. Ainda aqui o diálogo pode ser proveitoso, porque o juiz ou o tribunal, mesmo por hipótese imparcial, muitas vezes não se apercebe ou não dispõe de informações ou elementos capazes de serem fornecidos apenas pelos participantes do contraditório.

Como bem se posiciona Vittorio Denti, a respeito da exceção, pouco importa a iniciativa de sua argüição: o juiz, quando a examina de ofício, encontra-se, no concernente à exigência do contraditório, na mesma posição da parte. E se a determinação do objeto do juízo decorre do exercício de um específico poder processual do juiz e das par tes, o ato de exercício de tal poder não pode deixar de ter idêntica natureza, como ato de impulso processual, homólogo à demanda.

Assim, se é inafastável o contraditório em relação às exceções das partes, por análogas razões não se pode dele prescindir com referência às exceções examináveis de ofício: ambas, efetivamente, enquanto dão lugar a questões prejudiciais, apliam o the ma decidendum sobre o qual as partes têm direito de se manifestar ${ }^{21}$

Aliás, em face da posição doutrinária e jurisprudência dominantes na Itália, a recente lei italiana $\mathrm{n}^{\circ} 353$, de 26 de novembro de 1990 (a chamada novella del 1990) ${ }^{22}$, cujo art. 17 substitui o art. 183 do Codice de Procedura Civile, estabelece em sua alínea 3 que "O juiz solicita às partes, com base nos fatos alegados, os esclarecimentos necessários, e aponta as questões cognoscíveis de ofício sobre as quais entende oportuno recaia a discussãon.

Também em França não se tem entendido de forma diversa, consoante o excelente resumo realizado por Aroldo Plínio Gonçal 
ves $^{24}$, reproduzido a seguir em suas linhas essenciais, por sua adequação ao tema do presente trabalho.

Neste sentido, dispõe o atual art. 16 do Noveau Code de Procédure Civile: "Le juge doit en toutes circonstances, faire observer et observer lui-même le principe de la contradiction." A nova redação provocou o retorno aos textos de 1971 e 1972, pois a sua alínea 1 $1^{\underline{a}}$, que dispensava o juiz de observar "le principe de la contradiction des débats losqu'il reléve d'office un moyen de pur droit", foi anulada por decisão do Conseil d'Etat, em 12.10.79, após reação de várias associações de advogados.

Revigorou-se, assim, o antigo texto de 1971, que proibia o juiz de fundar sua decisão "sur les moyens de droits autres que d'or dre public qu'il a relevés d'office ou sur les explications complémentaires qu'il a demandées sans avoir au préalabre invité les parties présenter leurs observations."

Note-se que os Moyens designam, consoante autorizada doutrina francesa, mencionada por Aroldo Plínio Gonçalves, não apenas motivos e fundamentos, mas os meios de convencimento em geral.

4. Por isso, em tais hipóteses, impõe-se ao juiz prudente diálogo com as partes, seja chamando-as a seu gabinete para uma conversa informal (à moda do famoso processo de Stuttgart), a qual inclusive encontr apoio no direito positivo brasileiro, em vista da aplicação analógica dos arts. 447 e 45 do $\mathrm{CPC}^{25}$, seja suscitando nos autos a possibilidade de aplicação de tal ou qual norma, ou o exame da questão sob determinad perspectiva jurídica inovadora, ou informando ainda da possibilidade de ser apre ciada, de ofício, questão totalmente nova desconhecida dos litigantes.

Como se constata, mostra-se insuficien te, no contexto delineado no presente trabalho, a velha definição da garantia do contraditório. O princípio deve ter po conteúdo também a oportunidade concedi$\mathrm{da}$ às partes para se manifestarem, em prazo razoável, sobre todas as questões de fato de direito essenciais para a decisão da causa pouco importando que seu exame decorr de decisão voluntária do órgão judicial, ou por imposição da regra iura novit curia.

Cumpre assinalar, finalmente, que a problemática ora abordada não está ligada apenas ao interesse das partes, mas encontra íntima conexão com o próprio interesse público, na medida em que qualquer surpresa, qualquer acontecimento inesperado, só faz diminuir a fé do cidadão na administração da justiça ${ }^{26}$. O diálogo judicial torna-se, no fundo, dentro dessa perspectiva, autêntica garantia de democratização do processo, a impedir que o poder oficial do órgão judicial e a aplicação da regra iura novit curia venham a se transformar em instrumento de opressão e autoritarismo, servindo às vezes a um mal explicado tecnicismo, com obstrução à efetiva e correta aplicação do direito.

\section{Notas}

${ }^{1}$ Cf. Elio Fazzallari, Processo (Teoria Generale), em Nuovissimo Digesto Italiano, XIII, ristampa, Torino, Utet, 1982, págs. 1067-1076, esp. págs. 1069 e 1072. Antes, do mesmo autor, com igual visão crítica, Diffusione del Processo e Compiti della Dottrina, em Revista Trimestrale Erocedura Civile 12(1958):861-880.

${ }^{2}$ Emilio Betti, Diritto Processuale Civile, $2^{\mathbf{a}}$ ed., Roma, Foro Italiano, 1936, págs. 88-89. Mais recentemente, Proto Pisani, com farta indicaçào bibliográfica, indica a dupla função assumida pelo contraditório, garantindo de um lado a igualdade entre as partes e, de outro, satisfazendo o interesse público na descoberta da verdade e realização da justiça. Adverte, contudo, reportando-se a ensinamento de Carnelutti, que esta última só pode ser alcançada mediante a efetiva atuaçào do contraditorio e não por meio de sua mera possibilidade. (Dell' Esercizio dell' Azione, em Commentario del Codice di Procedura Civile, dirigido por E. Allorio, vol. I, tomo II, Torino, Utet, 1973, págs. 1.085-1.086.)

3 Por isso mesmo, constitui o contraditório poderoso fator de contenção do arbitrio por parte do juiz, e a experiência histórica demonstra que, a exemplo do ocorrido com Frederico, o Grande, a a exemplo do fissão de advogado resulta sempre infrutífera por estimular, entre outros inconvenientes, o excessivo poder do órga judicial. Cf a respeito, a notivel monoder do orgão judicial. Cf., a respeito, a notavel monografia (19) págs. 44-45, passim

${ }^{4}$ Sobre o ponto, as excelentes considerações desenvolvidas por P. Calamandrei, Processo e Democrazia, em Opere Giuridiche (aos cuidados de Mauro Cappelletti), I, Napoli, Morano, 1965, págs. 618-702, pág. 679.
5 Calamandrei, ob. e loc. cits.

${ }^{6}$ Sobre o tema e a distinção esboçada no texto, vide a relevante contribuição de Tito Carnacini, Tutela Giurisdizionale e Tecnica del Proceso, em Studii in Onore di E Redenti, II, Milano, Giuffré, 1951, págs. 695-772. Aind sobre a questão, as considerações críticas de $\mathrm{M}$. Cappelletti, La Testimonianza della Parte nel Sistema del Oralita (Contributo alla Teoria della Utilizzazione Prob toria del Sapere delle Parti nel Processo Civile), I, $2^{\mathbf{z}}$ ed. Milano, Giuffré, 1974, pág. 303 e segs.

7 Cf. a excelente monografia de José Roberto dos Santos Bedaque, Poderes Instrutórios do Juiz, São Paulo RT, 1991, págs. 85-95, passim, em que o autor, armado com bibliografia da melhor qualidade, examina profundamente o problema. Assim também José Carlos Barbosa Moreira, $A$ Garantia do Contraditório na Ativdade de Instrufão, em Temas de Direito Processual (Te ceira Série), São Paulo, Saraiva, 1984, págs. 65-77, esp. págs. 74-76, e o Problema da "Divisäo do Trabalbo" entre Juiz e Partes: Aspectos Terminológicos, em Temas Dircito Processual (Quarta Série) Sa Paulo Saraiva, 1989 , págs. $35-44$, esp. pág. 38 , item 4 .

8 Guardam toda pertinência as observaçōes, sobre a matéria, de Troller, Grundlagen, cit., págs. 76, reproduzidas no texto.

9 Cf. Mauro Cappelletti, Testemonianza, cit., págs. 34 350. Veja, a esse respeito, o interessante trabalho Antônio Janyr Dall'Agnol Júnior, $O$ Princípio Dispositivo no Pensamento de Mauro Cappelletti, em Ajuris, 46(1989):97-115. Assim também a doutrina francesa, exemplo de Henri Motulsky, Le Rôle Respectif du Juge des Parties dans l'Allégation des Faits em Etudes a No des Parties dans lAillegation des Faits, em Etudes et Notes de Procédure Civile, Paris, Dalloz, 1973, págs. 38.57, que na pode fundar sua decisa a na ser nos fato pente introduzidos pelas partes.

${ }^{10}$ Por isso mesmo, Alois Troller, Grundlagen, cit., pá 76 , depois de profundo exame histórico das relaçõe de poder dentro do processo, não pôde deixar de concluir que "(...) o importante princípio 'Da mibi factum dabo tibi ius ainda domina tăo somente por sua autoridade histórica, que não pode lhe conferir o poder inibir o direito material atual."

11 Veja a respeito as interessantes observações de Fritz Baur, Da Importância da Dição "Iuria Novit Curia", em Baur, Da Importancia da Diçao "I169-177, O Cura", em Revista de Processo, 3(1976):169-177, o qual chega, inporantes conclusões a respeito do tema: a) a diç̧o iuria noit curia na significa que a obrigacá das iuria novil curia náo significa que a obrigaçao das par prova estao sempre exclúdos, no que diz respito as prova estao sempre exchidos, no que diz respetio as normas juridicas aplicaveis, tendo em vista un litigio; b) a dicção iuria novit curia não significa que o tribunal disponha do monopollo da aplicaçáa do direito, desconhecendo ou desprezando as conclusôes das partes tendo em vista as normas juridicas invocadas pelos litigantes; c) a diç̧ão iuria novit curia não significa que pertence ao tribuna o direito de fazer abstra- ção de lei, em função de referência feitas aos princípios de eqüidade, menos apropriados à solução do litígio.

12 F. Baur, ob. e loc. cits.

13 Segundo James Goldschmidt, Der Prozess als Rechts. lage (Eine Kritik des Prozessualen Denkens), reimpressão da 2 ed., Aalen, Scientia Verlag, 1986, pag. 425, não são sequer afirmaçôes e nem objeto de um onus forma de afirmação, o que nảo exclui sejam atos de obtenção em sentido amplo e até participaçôes de conhecimento.

${ }^{14}$ Assim, Eduardo Grasso, La Collaborazione nel Proces. so Civile, em Rivista di Diritto Processuale, 21(1966):580 609, esp. pág. 587. A idéla de colaboraçăo e largamente desenvolvida por Grasso com vistas a que o processo ultrapassando o simples escopo da paz jurídica, seja também inspirado pela busca da verdade e da justiça, só alcançável, segundo ele, mediante a colaboração entre as partes e o juiz. Tudo isto, porém, é muito relativo, na medida em que se deixe de entrever princípio do contraditório só na perspectiva do ato introdutivo do processo (como decorre da letra expressa do art. 101 do CPC italiano) e se passe a referi-lo a todo o processo. Nessas condiç̧ees, a distinção, como bem adverte Proto Pisani, Dell' esercizio dell' azione, cit. pág. 1086, torna-se em grande parte terminológica.

15 Sobre o ponto, vide Carlos Alberto Alvaro de Oliveira, Alieną̧ão da Coisa Litigiosa, 2!a ed., revista, atuaveira, Aliená̧ão da Coisa Litigiosa, 2- ed., revista, atua-
lizada e aumentada, Rio, Forense, 1988, págs. 51-55.

${ }^{16}$ Cf., neste sentido, A Arndt, Die Verfassungsbeschwerde wegen Verletzung des rechtlichen Gebors, págs. 1297 e segs. 1301, apud, N. Trocker, Processo Civile e Constituzion (Problemi di Diritto Tedesco e Italiano), presentazione di Gian Antonio Micheli, Milano, Giuffré, 1974, págs. 644 645; para outras referências bibliográficas, esp. pág. 645 , nota 9.

${ }^{17}$ Assim o pronunciamento do Bundesverfassungsgericht (Tribunal Constitucional Federal) alemão na decisão no 6 de 18.6.1957, em conexão com a decisão no 9 de 8.1.1959, segundo a citação de N. Trocker, ob. cit. ágs 641-642 e nota 7. Consoante menciona Walter Zeiss, Zivilprozesstecht, $7^{ \pm}$ed., Tübingen, J.C.B. Moher (Paul Siebeck), 1989, pág. 75, o Tribunal Constitucional Alemão tem considerado que na decisão só se admite o emprego de material processual sobre o tenha sido concedido direito de audiência (BVerfG 19 142(144)). Assim também a decisão do BVerfG referida 142(144)). Assim tambem a decisão do BVerfG referida por Gerhard Walter, Libre Apreciacion de La Prueba mites del Libre Convencimiento Judicial) mates del Libre Convencimiento Judicial), trad. de Tomás Banzhaf, Bogota, Temis, 1985, pag. 386, em que a Alt Córte alemà assentou abarcar o principio do contradpesquisas judicias e todos os resultados das diligências probárias, inclusive os "fatos conhecidos pelo tribunal" (NJW, 1960, 31).

${ }^{18} \mathrm{Cf}$ a a clássica definição de Joaquim Canuto Mendes de Almeida, A Contrariedade na Instrusão Criminal 1937, pág. 110, apud, José Frederico Marques, Institucóes de Direito processual Civil, vol. II, $4^{a}$ ed. revista, Rio, Forense, 1971, no 311 , pág. 97 e nota 114 . 
19 Cf. Wolfgang Grunsky, Grundlagen des Verfabrensrechts (Eine vergleichende Dartellung von ZPO, FGG, $V w G O, F G O, S G G)$, 2. neubearbeitete Auflage, Bielefeld, Giesekig Verlang, 1974, § 25, III, págs. 232-234. Aliás, em atenção a esses conceitos, completamente pacificados na doutrina $e$ jursiprudência da então Alemanha Federal, incorporou esta ao seu direito positivo, quando da reforma processual de 1977 , sob o $\S 278$, III, da Ordenança Processual Civil (ZPO), o dispositivo a seguir reproduzido em tradução livre: "O juiz só pode apoiar sua decisão em um aspecto jurídico considerado insignificante pela parte, ou que lhe tenha passado desapercebido, se lhe tiver dado oportunidade de manifestar-se a respeito, salvo quando se tratar de uma questão meramente acessória."

20 Veja-se, ainda aqui, Grasso, La Collaborazione nel Processo Civile, cit., pág. 605

21 Vittorio Denti, Questioni Rilevabili d'Ufficio e Contraddittorio, em Rivista di Diritto Processuale, 23(1968):217-231, esp. pág. 224. Proto Pisani, Dell'esercizio dell'azione, cit., pág. 1088, encampa o entendimento, com menção expressa a todos os atos com os quais se alarga o thema decidendum, sejam exceçōes de mérito ou processuais, questōes de fato ou de direito, exercidas pela parte ou relevadas de oficio pelo juiz.

22 Ver a excelente tradução de José Rogério Cruz e Tucci, no apêndice de Devido Processo Legal e Tutela Jurisdicional, Rogério Lauria Tucci e José Rogério Cruz e Tucci, São Paulo, RT, 1993, págs. 231-261.

23 Como bem sublinha Sergio La China, Diritto Processuale Civile: La Novella del 1990 (Appunti per gli studenti), Milano, Giuffre, 1991, pag. 31, ao comentar a regra mencionada, "(..) il giudice puo, anzi deve, indicare le questioni rivelabili d'ufficio delle quali ritiene opportuna la trattazione: questioni, aggiungiamo noi, che possono essere cosi processuali como sostanziali - ad es., una questione di giurisdizione, una questione di nullita del contratto. Voglia. mo qui richiamare lattenzione sull importanza di questa indicazione ad opera del giudice delle questioni che egli ritiene di poter rilevare anche d'ufficio, perché è un modo di evitare sorprese alle parti, mettendole subito a conescenza dei dubbi che agitano la mente del giudice e consentendo cosi a lui come ad esse di approfondire la questione prospettata, prima che si arrivi ad un vero e proprio e formale rilievo d'ufficio."

${ }^{24}$ Aroldo Plínio Gonçalves, Técnica Processual e Teoria do Processo, Rio, Aide, 1992, pág. 123, nota 176, com farta menção à doutrina e ao entendimento pacífico da jurisprudência francesas, valendo ressaltar aqui a decisão no sentido de que "o tribunal não pode levantar de oficio un moyen não invocado pelas partes e sobre o qual uma delas não haja sido chamada a se manifestar."

25 Deve-se reconhecer, porém, a resistência oferecida tanto por juízes quanto por advogados, à adoção prática das providências recomendadas em tais regras de lei.

${ }^{26}$ Cf. a certeira observação de N. Trocker, ob. cit., pág. 669 .

184

\section{Instrumental alternativo}

\section{Pequena contribuição}

\section{Rui Portanova}

Juiz de Direito da Comarca de Porto Alegre,

Professor da UFRGS e FEMARGS.

SUMÁRIO

Intodução; Primeira parte: aspectos gerais do direito; 1. Dimensões do Direito; 2. Função Social do Direito; 3. Incidência; 4. Lacunas do Direito; 5. Abuso de Direito; 6. Princípios gerais do Direito; Segunda parte : aspectos do direito em espécie; 1. Obrigaçōes; 2. Onerosidade Excessiva; 3. Incidência; 4. Função social da propriedade; 5. Direito comercial; 6. Escopos e efetividade do processo; Conclusão.

\section{Resumo}

$\mathrm{Na}$ atualidade a atividade jurídica brasileira apresenta-se dúplice. Numa mesma realidade convivem duas formas de encarar as solucões jurídicas. De um lado uma visão tradicional do direito, influenciada ainda pelo positivismo legalista. De outro lado, uma forma crítica, no Brasil chamada alternativa. O presente trabalho traz alguns dos instrumentos jurídicos utilizados por uma visão alternativa do direito, os quais flexibilizam a aplicação do direito com vistas a uma atuação centrada na justiça social.

\section{Introdução}

O chamado movimento do direito alternativo, no Brasil, não é, ainda,uma teoria que pode ser praticada, mas uma prática que deve ser teorizada. Os fundamentos e os aspectos gerais desta forma de atuação do direito são melhor compreendidos no confronto com a visão majoritária sustentada e praticada no Brasil aqui chamada tradicional. Seguem, por oportuno, as distinções entre uma visão tradicional e alternativa do direito. No meu livro "Motivações Ideológicas da Sentença" tais considerações são mais largamente apresentadas.
Tradicionalmente o direito vê o mundo e a sociedade vivendo em igualdade, harmonia, paz; ordem, justiça e segurança. $O$ egislador, atento a estas características, prevê na lei: fatos que quebram a harmonia social e sanções a serem impostas pelo Poder Judiciário ao responsável pelo conflito. $\mathrm{O}$ juiz, assim, está vinculado à lei que é a expressão da justiça. A função do juiz é a conforme a vontade da lei" (Santos. M 1984 p.333). Já uma visão crítica ou alternativa do direito vê a sociedade em permanente conflito e vivendo em desigualdade, tanto que dividida em classe. Há uma crise do direito proveniente do fato de que nossa realidade não é aquela que embasou grandes teorias do passado. Logo,os tradicionais pressupostos metodológicos (principalmente a lei como unidade formal capaz de equilibrar antagonismos e harmonizar interesses) sofrem um processo de revisão (Faria, 1988, p.14). Há uma crescente demanda de direitos não legislados (o de morar, por exemplo) nascidos das mobilizações e organizações comunitárias e populares. Um Judiciário tradicional não tem instrumentos materiais e formais para atender tais reivindicações.

$\mathrm{Na}$ visão tradicional, a lei consagra os avanços e as necessidades sociais, organizando as aspirações do povo. Por isto, ao juiz de "compor conflitos com justiça, isto é,

R. Fac. Direito UFRGS, Porto Alegre, 9(1): 185-200, nov. 1993 